\title{
Metalotioninas en Perna viridis (Bivalvia: Mytilidae): variación estacional y su relación con la biología reproductiva
}

\author{
Mairin Lemus ${ }^{1,4}$, Nilis Rojas ${ }^{2}$, Luisa Rojas-Astudillo ${ }^{3}$ \& Kyung Chung ${ }^{4}$ \\ 1. Departamento de Biología, Escuela de Ciencias, Universidad de Oriente, Núcleo de Sucre, Cumaná 6101, Venezuela; \\ mlemus88@gmail.com \\ 2. Postgrado en Biología Aplicada, Universidad de Oriente, Núcleo de Sucre, Cumaná 6101, Venezuela; \\ nilisrojas@gmail.com \\ 3. Departamento de Química, Escuela de Ciencias, Universidad de Oriente, Núcleo de Sucre, Cumaná 6101, Venezuela; \\ 1rojas40@yahoo.com \\ 4- Laboratorio de Ecofisiología. Departamento de Biología Marina, Instituto Oceanográfico de Venezuela, Cumaná 610; \\ kyungsukchung@gmail.com
}

Recibido 19-III-2012. Corregido 18-IX-2012. Aceptado 18-X-2012.

\begin{abstract}
Metallothioneins in Perna viridis (Bivalvia: Mytilidae): seasonal variation and its relation to reproductive biology. Metallothionein is a cytosolic protein found in a variety of tissues and have been involved in the regulation of essential trace metals such as copper and zinc, and in the detoxification of essential and nonessential metals. With the aim to study their seasonal variation and their possible role in reproductive behavior, we evaluated metallothioneins (Mts) in Perna viridis, taken from Rio Caribe and Chacopata localities in the North coast of Sucre state, Venezuela. A total of 325 samples were obtained from February to December 2003. We determined the following biometric indices in bivalves: Condition Index (CI), meat yield (RC) and dry weight-length relationship (PSL). Besides, Mts in whole tissue were separated by molecular exclusion chromatography, Sephadex G-50 and quantified by saturation with cadmium. Our results showed that the biometric indices (RC and PSL) had seasonal variations between localities and maturity stages, with the exception of IC. No significant differences were found between sexes. Mts showed seasonal variations between localities, with the highest concentrations between February and March, and minimum ones between September and December, coinciding with the respectively high and low productivity periods in the area. The mussels from Rio Caribe had higher Mts concentration than those from Chacopata. Furthermore, immature mussels showed the highest Mts concentration while the lowest was found in spawned specimens. We found a significant negative relationship between Mts and CI. Our results demonstrated that MTs in Perna viridis are influenced by the condition index and reproductive status, as well as physico-chemical factors in the marine environment. Rev. Biol. Trop. 61 (2): 701-709. Epub 2013 June 01
\end{abstract}

Key words: metallothionein, biometric indices, gametogenic cycle, Perna viridis.

Las metalotioninas (Mts) son proteínas de baja masa molecular, con aproximadamente 6000 a $7000 \mathrm{Da}$, de unas 20 cisteínas aproximadamente, y que enlazan siete metales divalentes (Kojima 1991). Estas proteínas juegan un importante rol en la detoxificación de metales (Cajaraville et al. 2000, Amiard et al. 2006, Ng et al. 2007, Baraj et al. 2011), por lo que tienen un papel ecotoxicológico importante, ya que su síntesis constituye una respuesta específica a elevadas concentraciones de metales; de ahí que su empleo como un potencial biomarcador de contaminación (Sureda et al. 2011). Hasta el momento, los trabajos que sustentan estos resultados, en su mayoría, han sido realizados bajo condiciones controladas, tanto para los organismos (talla, sexo, edad), como para factores como temperatura, niveles tóxicos de los metales inductores y otros. Así, los estudios en ambientes naturales son escasos 
y controversiales, pues actualmente se ha determinado que muchos factores podrían modular la expresión de las Mts en ambientes naturales y podrían enmascarar las respuestas derivadas de la presencia de metales (Soo-Kyung et al. 2003, Long et al. 2010). Esto ha determinado que dichas proteínas sean evaluadas con mucho cuidado en ambientes naturales, debido a lo poco que se conoce sobre el papel que éstas juegan en el ciclo de vida de los organismos marinos y particularmente en bivalvos (Bordin et al. 1997, Legras et al. 2000).

Los mecanismos involucrados en la metabolización de $\mathrm{Zn}$ y Cu por las MTs no están dilucidados, sin embargo, se conoce que el ATP y el disulfuro de glutatión (GSSG) son moduladores que permiten la disociación del $\mathrm{Zn}$ de la MTs de acuerdo a los requerimientos de apoenzimas (Li-Juan et al. 1998). Es por ello que las Mts pueden estar afectadas por el balance redox de la célula, factores externos del ambiente (como lo son la temperatura, salinidad y disponibilidad de alimento) y por factores bióticos relacionados con el metabolismo de los organismos (como lo son la condición reproductiva, sexo y peso) (Legras et al. 2000, Leung et al. 2002, Farcy et al. 2009). Por lo anterior, esta proteína está sujeta a variaciones determinadas por múltiples efectores que determinan su concentración celular.

El papel homeostático de las Mts en la fisiología de bivalvos marinos es una materia poco conocida, particularmente con lo relacionado a los niveles naturales durante el desarrollo y ciclo reproductivo de bivalvos. Sin embargo, durante el proceso de maduración gonadal, ocurre la activación de numerosas enzimas en los procesos metabólicos relacionados con la proliferación, por lo que se esperaría que las Mts modularan la concentración en función a la demanda de proteínas o enzimas involucradas en el desarrollo gonadal. El zinc juega un importante papel en la expresión génica: induce enzimas que participan en la síntesis de $\mathrm{ADN}$, tanto durante el proceso de división celular y la diferenciación celular; también estabiliza la estructura del ADN y ARN e influye en su síntesis y degradación; participa en la regulación hormonal: influye en la síntesis y secreción de hormonas y modula también la actividad periférica de hormonas (Coleman 1992, Prasat 1995). Por otro lado, el cobre, participa en numerosas reacciones de oxidación-reducción de las enzimas, es un componente importante de la citocromo oxidasa-lisina oxidasa, $\mathrm{Cu} / \mathrm{Zn}$ superóxido dismutasa, la dopamina b-hidroxilasa, ceruloplasmina y la tirosinasa-oxidasa catecol (Uauy et al. 1998).

El mejillón verde, Perna viridis, es una especie invasora, reportada por primera vez en Venezuela hace 20 años (Rylander et al. 1996) y ha logrado extenderse a lo largo de la costa del estado Sucre, desplazando a Perna perna. $P$. viridis presenta desoves continuos, aunque con mayor reclutamiento durante el primer semestre del año y un reclutamiento secundario en septiembre (García et al. 2005, Acosta et al. 2010). En este trabajo se evaluaron los niveles de Mts en el bivalvo P. viridis en diferentes estadios de desarrollo gonadal y su relación con algunos índices biométricos, en dos localidades de la costa norte del estado Sucre, donde ha logrado establecerse exitosamente y donde la influencia antrópica es diferente.

\section{MATERIALES Y MÉTODOS}

Captura y selección de organismos: Los ejemplares de Perna viridis fueron recolectados mensualmente por buceo autónomo en la zona intermareal de las localidades de Chacopata, (10³6'40” N - 6345’33” W), y Río Caribe, $\left(10^{\circ} 41^{\prime} 03^{\prime \prime} \mathrm{N}-63^{\circ} 06^{\prime} 00^{\prime \prime} \mathrm{W}\right)$ desde enero hasta diciembre 2003, realizando los muestreos a los 15 días de cada mes.

Un total de 30 especímenes vivos fueron transportados en contenedores isotérmicos hasta el laboratorio de Ecofisiología, donde se evaluó un total de 325 ejemplares, 165 provenientes de la localidad de Chacopata y 160 de la localidad de Río Caribe. A los organismos colectados se les tomaron sus características biométricas como el largo, ancho y alto de la concha con un vernier digital (QL-V8), la masa del tejido blando en una balanza PCE-LS, el sexo y los estadios reproductivos se realizaron 
según las características macroscópicas de maduración sexual para $P$. viridis (Narasimhan 1980). Se agruparon en juveniles (I inmaduros) que presentaron la gónada moderadamente desarrollada, con talla promedio de $28 \pm 10 \mathrm{~mm}$ y adultos (maduro II y desove III) con talla promedio de $79 \pm 14 \mathrm{~mm}$. Los organismos que estaban en la fase de regresión gonadal no fueron considerados en esta experiencia.

Con los parámetros biométricos se determinaron las relaciones alométricas mensuales entre el peso seco total (Ps) con la longitud total (Lt) utilizando la ecuación $\mathrm{Ps}=\mathrm{aLt}^{\mathrm{b}}$, donde a es el intercepto y b es la pendiente de la recta (Wilburg \& Owen 1964); el índice de condición $\left(\mathrm{IC}=[\mathrm{Ps} / \mathrm{Ph}]^{*} 100\right)$ donde $\mathrm{Ph}$, es el peso húmedo de la carne e índice de rendimiento en carne $\left(\mathrm{RC}=(\mathrm{Ph} / \mathrm{P})^{*} 100\right)$ donde $\mathrm{P}$ es el peso total, según Hickman \& Illingworth (1980).

Separación de metalotioninas: Se prepararon extractos crudos del tejido blando de cada organismo, homogeneizando $1 \mathrm{~g} / \mathrm{mL}$ de buffer Tris-HCl 10mmol/L, 2-mercaptoetanol $10 \mathrm{mmol} / \mathrm{L}$ a pH 8.6 usando un homogeneizador Polytron modelo Brinkmann. Los homogeneizados fueron saturados con $\mathrm{CdCl}_{2} 0.5 \mathrm{mg} /$ $\mathrm{mL}(0.2 \mathrm{~mL} / \mathrm{mL}$ de homogeneizado), durante $30 \mathrm{~min}$, a temperatura ambiente (Lacorn et al. 2001) y centrifugados $\left(4^{\circ} \mathrm{C}, 90 \mathrm{~min}\right.$, $15000 \mathrm{~g})$. Del sobrenadante se tomó $1 \mathrm{mg}$ de proteínas, determinado previamente, de acuerdo a Bradford (1976), para realizar el fraccionamiento cromatográfico en una columna $(25 \times 1.5 \mathrm{~cm})$ con Sephadex G-50, previamente calibrada con marcadores de masas moleculares conocidas (Sigma MV. GF-70): Anhidrasa carbónica $29000 \mathrm{KDa}$; Citocromo C, 12 000KDa; Aprotinina B 6 500KDa y Vitamina B12 $1350 \mathrm{KDa}$. Las muestras fueron eluidas a un flujo de $2 \mathrm{~mL} / \mathrm{min}$ con una solución buffer de $\mathrm{Na}_{2} \mathrm{HPO}_{4} 20 \mathrm{mmol} / \mathrm{L}, \mathrm{NaCl} 10 \mathrm{mmol} / \mathrm{L}, \mathrm{NaN}_{3}$ $0.02 \%$, a pH 7. Una vez obtenidas las fracciones, se determinó la presencia de proteínas en un espectrofotómetro Termo Spectronic He $\lambda$ ios a $280 \mathrm{~nm}$. Los datos se expresaron en $\mu \mathrm{g}$ de Mts por mg de proteína total ( $\mu \mathrm{g}$ MTs/mg)
Determinación de grupos sulfidrilos: Para la determinación de los grupos sulfidrilos (SH) se utilizó la reacción de Ellmann (1959). A $100 \mu \mathrm{L}$ de cada fracción eluída de la columna de Sephadex G-50 se adicionó $400 \mu \mathrm{L}$ de ácido ditionitrobenzoico (DTNB) (33mg DTNB en $50 \mathrm{~mL}$ de buffer fosfato $120 \mathrm{mmol} / \mathrm{L}, \mathrm{pH} 7.5$ ), se mezclaron, y reposaron durante 10 minutos. La absorbancia se registró a $412 \mathrm{~nm}$, en un espectrofotómetro Milton Roy Spectronic 21D.

Determinación de las concentraciones de cadmio: Las concentraciones de cadmio provenientes de las fracciones obtenidas por cromatografía, se acidificaron con $\mathrm{HNO}_{3}$ (Suprapur) $2 \%$ y ajustó $\mathrm{pH} 4$ con $\mathrm{NaOH}(0.5$ $\mathrm{mol} / \mathrm{L}$ ) y se determinaron por potenciometría (pHmetro Orion modelo 720 A11 acoplado a un electrodo Cole-Palmer ${ }^{\circledR}$ 27502-06), para evitar interferencias por carga de transporte de los iones $\mathrm{H}_{3} \mathrm{O}^{+}$. La respuesta del electrodo fue lineal $\left(\mathrm{R}^{2}=0.997\right)$ a la actividad del ión $\mathrm{Cd}^{2+}$ en un intervalo de $1.0 \times 10^{-1}$ a $1.0 \times 10^{-6} \mathrm{~mol} / \mathrm{L}$.

Electroforesis SDS-PAGE: A las fracciones que enlazaron metal y presentaron grupos sulfidrilos, se les realizó una electroforesis SDS-PAGE según la metodología descrita por Eriksen et al. (1988). Se estimó la masa molar aparente de la metalotionina a partir de una curva de calibración realizada con un kit MWSDS-70 (Sigma) y metalotionina de hígado de rata (SIGMA), a través de la distancia relativa recorrida por la muestra con respecto a la distancia recorrida por el frente del disolvente (Rf). La masa molar aparente calculada para la metalotionina fue de $12000 \mathrm{KDa}$.

Las concentraciones de Mts en las fracciones de máximo enlazamiento de cadmio fueron cuantificadas siguiendo el método propuesto por Lacorn et al. (2001).

Se realizó un análisis multifactorial para determinar las diferencias entre los índices biométricos y las Mts entre localidades, meses, sexo y estado de madurez. A las que resultaron estadísticamente diferentes se les aplicó pruebas de comparación de medias LSD (Sokal \& Rohlf 1995), se establecieron correlaciones 
entre los índices y estados de madurez. Estos análisis fueron realizados a través del programa STATGRAPHIC Plus versión 5.1.

\section{RESULTADOS}

A partir de los análisis biométricos realizados a $P$. viridis provenientes de dos localidades de la costa norte del estado Sucre, se pudo determinar que el RC, IC y PSL presentaron diferencias significativas espaciales y temporales; sin embargo, entre sexos no se encontraron diferencias significativas. El RC y la PSL presentaron diferencias significativas para los diferentes estadios de madurez (Cuadro 1).

El IC fue significativamente superior en la localidad de Río Caribe, con un valor de $22.17 \pm 2.40$, mientras en cada localidad de Chacopata fue de 21.30 \pm 1.14 ; por su parte, el RC fue superior en la localidad de Chacopata, con un valor promedio anual de $35.57 \pm 6.62$, y para la localidad de Río Caribe fue de 28.00土8.15, un comportamiento similar fue observado para el PSL (Fig. 1).

Las variaciones mensuales del IC fueron mucho más pronunciadas en Río Caribe en relación a Chacopata, donde los valores se mantuvieron similares en todos los meses de muestreo (Fig. 1). Durante los meses de febrero, marzo y abril hubo un descenso significativo del IC en Río Caribe, el cual se incrementó en los meses sucesivos y se mantuvo elevado posteriormente durante el período de agosto a diciembre.

Con respecto al $\mathrm{RC}$, no se encontraron grandes variaciones en la localidad de Chacopata, sin embargo, se produjo una caída durante el mes de octubre. En Río Caribe el índice presentó mayores variaciones, con tres descensos
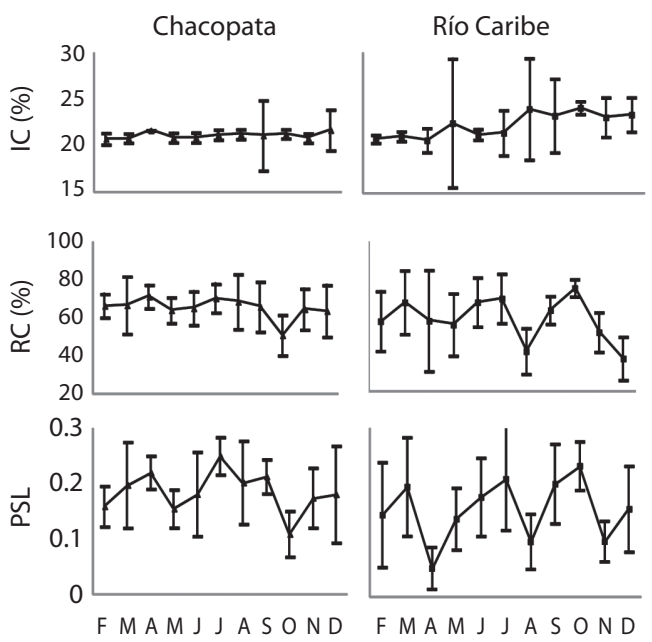

Meses 2003

Fig. 1. Variación mensual del Índice de condición (IC), Rendimiento en carne (RC) y relación peso seco-longitud (PSL) en Perna viridis proveniente de las localidades de Chacopata y Río Caribe, estado Sucre, Venezuela.

Fig. 1. Monthly variation in condition index, meat yield and dry weight-length relation of Perna viridis from the Chacopata and Río Caribe, Sucre state, Venezuela.

CUADRO 1

Análisis de varianza multifactorial de índices biométricos en Perna viridis provenientes de la localidad de Chacopata y Río Caribe, estado Sucre

TABLE 1

Multifactorial analysis of variance in biometric index of Perna viridis from Chacopata and Río Caribe, Sucre state

\begin{tabular}{lccccccc} 
& \multicolumn{2}{c}{ IC } & & RC & & PSL & \\
& F & & $P$ & $\mathrm{~F}$ & $P$ & $\mathrm{~F}$ & $P$ \\
Localidad & 19.94 & $\mathrm{p}<0.05$ & 19.62 & $\mathrm{p}<0.05$ & 6.40 & $\mathrm{p}<0.05$ \\
Sexo & 1.07 & $\mathrm{p}>0.05$ & 0.19 & $\mathrm{p}>0.05$ & 1.13 & $\mathrm{p}>0.05$ \\
Meses & 6.25 & $\mathrm{p}<0.05$ & 3.32 & $\mathrm{p}<0.05$ & 2.96 & $\mathrm{p}<0.05$ \\
Estadios de madurez & 1.00 & $\mathrm{p}>0.05$ & 8.30 & $\mathrm{p}<0.05$ & 7.28 & $\mathrm{p}<0.05$ \\
\hline
\end{tabular}

RC: rendimiento en carne, IC: índice de condición, PSL: relación longitud peso seco.

$\mathrm{RC}$ : meat yield, CI: condition index, PSL: dry weight-length relationship. 
significativos durante el año entre abril-mayo, agosto y diciembre (Fig. 1). La relación PSL mostró un comportamiento similar al observado en el IC.

Las Mts mostraron variaciones significativas entre las localidades $(\mathrm{F}=4.80, \mathrm{p}=0.0291)$, y los meses evaluados $(\mathrm{F}=17.68, \mathrm{p}=0.0000)$. Los niveles de Mts en los mejillones fueron significativamente mayores en Río Caribe, con un valor promedio de $0.873 \pm 0.490 \mu \mathrm{g}$ $\mathrm{Mt} / \mathrm{mg}$ con respecto a Chacopata que fue de $0.753 \pm 0.546 \mu \mathrm{g} \mathrm{Mt} / \mathrm{mg}$ (Fig. 2), y también con relación al estadio de madurez sexual $(\mathrm{F}=5.67$, $\mathrm{p}=0.004$ ), siendo los organismos desovados los que presentaron el menor valor promedio de esta proteína (Fig. 3). La concentración de estas proteínas entre sexos no mostró variaciones significativas.

Además de las variaciones espaciales de las Mts, también la concentración de esta proteína fue elevada para los primeros meses del año en las dos localidades, y disminuyó entre septiembre-diciembre (Fig. 2).

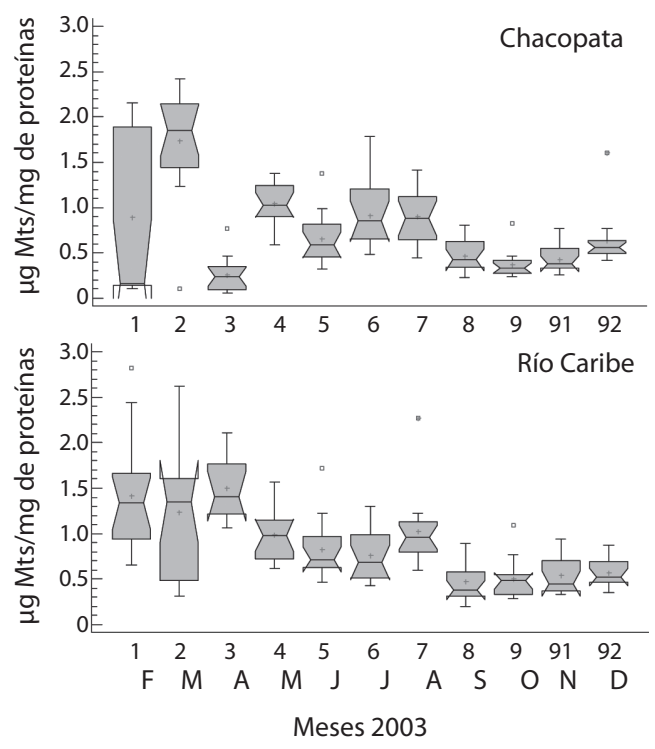

Fig. 2. Variaciones mensuales en las concentraciones de metalotioninas (Mts) en los tejidos de los mejillones Perna viridis de la localidad de Chacopata y Río Caribe, Estado Sucre, Venezuela.

Fig. 2. Monthly variations of metallothionein concentrations in the tissues of mussels Perna viridis from Chacopata and Rio Caribe, Sucre state, Venezuela.
Gráfico Caja y Bigotes

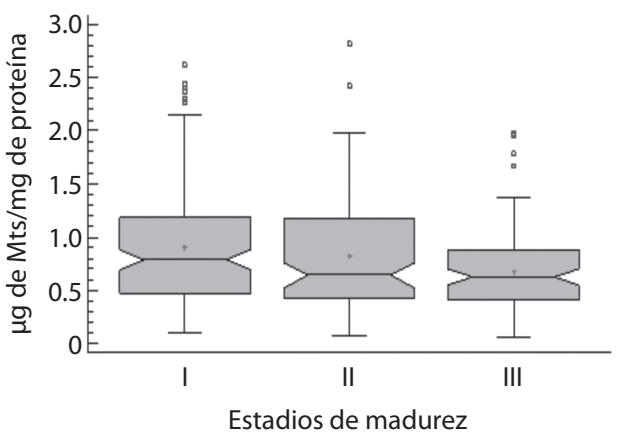

Fig. 3. Metalotioninas en los tejidos de los mejillones, Perna viridis en (I) inmaduros, (II) maduros, (III) desovados.

Fig. 3. Metallothionein in the tissues of the mussel, Perna viridis (I) immature, (II) mature, (III) spawned.

Finalmente, se estableció una relación estadísticamente significativa entre los niveles de Mts y el IC de la especie, donde la ecuación $\mathrm{Mts}=2.179-0.062 * \mathrm{IC}, \mathrm{F}=18.00$, $\mathrm{p}=0.0001$, señala que la condición reproductiva de la especie modula la variabilidad de los niveles de esta proteína, siendo menores en aquellos organismos que presentan un IC bajo y viceversa.

\section{DISCUSIÓN}

El índice de condición de $P$. viridis presentó valores inferiores $(22.17 \pm 2.40 \%$ y $21.30 \pm 1.14 \%$ para Río Caribe y Chacopata, respectivamente) a los determinados en esta especie proveniente del Morro de Guarapo, con un valor promedio anual de $29.37 \%$ (Arrieche et al. 2002). En otras poblaciones de $P$ viridis en la Isla de St. Mary cerca de Udupi se determinó un valor máximo en el IC comprendido entre 22 y 24 durante el mes de mayo, y las variaciones mensuales estuvieron asociadas con tres desoves de la especie con diferentes intensidades (Hemachandra 2008).

Aunque, el IC y los otros índices biométricos en $P$. viridis no mostraron diferencia entre sexos, otros bivalvos de la zona siguieron el mismo patrón de variación, pero han demostrado diferencias significativas. En poblaciones 
de P. perna provenientes de Guarapo, ubicada a $20 \mathrm{Km}$ de la localidad de Guayacán, el IC presentó diferencias entre meses, sexos, intervalos de longitud y estados de maduración sexual, registrándose la condición más baja en los individuos en fase de regresión gonadal, seguido de los estadios en fase de desove, maduración y maduro (Arrieche et al. 2002).

La gran variación mensual del IC en Río Caribe podría estar asociada a una elevada actividad reproductiva de los procesos de maduración y desove derivados de una elevada productividad de la zona (Müller-Karger et al. 1989). Por el contrario, en la zona de Chacopata, posiblemente se mantiene un aporte anual de seston con poca variación mensual que permite una muy baja variabilidad mensual en el IC y probablemente determine la ocurrencia de desoves continuos en esta localidad. Cuando esto ocurre, por lo general el IC no sufre variaciones significativas, mientras que el desove total de un organismo, está asociado a un IC bajo. Por ello se ha establecido que valores bajos del IC generalmente coinciden con la ocurrencia de desoves (Villalejo-Fuerte \& Ochoa-Báez 1993), es por ello que cuando estos ocurren de manera parcial suelen no evidenciarse grandes variaciones en el IC de bivalvos.

En varias localidades del oriente venezolano se han detectado dos o más desoves al año en $P$. viridis (Acosta et al. 2010) al igual que en otras latitudes, los patrones de reclutamiento son continuos y se extienden a dos o más picos por año (Kan et al. 2010). La relación PSL, muestra un patrón de comportamiento similar al mostrado en el RC para esta especie, lo que sugiere la gran dependencia con el desarrollo gonadal de la especie, se encontró que la especie presenta el mayor rendimiento en carne durante el período de lluvia, que se inicia en marzo, se intensifica en julio y continúan hasta el mes de octubre durante el período de muestreo, con un aumento en la temperatura comprendido entre 29 y $31^{\circ} \mathrm{C}$.

Las variaciones mensuales determinadas en los índices morfométricos, en el presente trabajo, señalan una mayor variación mensual de los parámetros analizados en Río Caribe.
Aunque las dos zonas están ubicadas en la costa norte del estado Sucre, esta última está sometida a máximas variaciones cíclicas que condicionan la actividad fisiológica de $P$ viridis. Hacia Río Caribe los afloramientos parecen ser más intensos, debido a la convergencia de los fenómenos de surgencia propios de la zona y la influencia marcada de las descargas del Delta del Orinoco (Müller-Karger et al. 1989, Varela et al. 2003), las cuales vienen acompañadas con gran cantidad de materia orgánica en suspensión que enriquecen el seston, mientras que se observa una disminución de los niveles de clorofila $a$ hacia la zona de Chacopata que está alejada en sentido este-oeste.

Particularmente, en P. viridis, el desarrollo gonadal se explica en gran parte por el seston total, a diferencia de $P$. perna en la cual el desarrollo está asociado en mayor parte a los niveles de clorofila $a$ (Acosta et al. 2010). Esto sugiere que la separación espacial en esta especie, juega un papel importante en la biología reproductiva. Esto ha sido demostrado para poblaciones de $P$. viridis en otras latitudes. Rajagopal et al. (1998) y Rajagopal et al. (2006), señalan que las tasas de crecimiento se ven influidas por factores ambientales, tales como temperatura, disponibilidad de alimentos y el movimiento del agua, por lo que las tasas de crecimiento varían entre localidades.

Los mayores niveles de Mts en los ejemplares de de Río Caribe podrían estar asociados a los mayores índices de condición presentados por los mejillones de esta zona, que además de estar influidas por los parámetros físico-quími$\cos$ y biológicos ya planteados anteriormente y que caracterizan a la zona como un centro de alta productividad primaria, en relación a Chacopata existe un aporte fluvial de materia en suspensión que puede aportar niveles significativos de metales producto de las industrias de metalurgia y explotación minera (GarcíaSánchez et al. 2006, Rojas et al. 2009).

Aunque no existen suficientes estudios que determinen el efecto de los factores físicoquímicos y biológicos sobre los niveles de esta proteína en ambientes naturales, Bordin et al. (1997), determinó que las Mts variaron 
significativamente con la estación en el bivalvo Macoma balthica, presentándose los valores más altos en invierno y los más bajos en verano. Los resultados aquí mostrados señalan también los valores más bajos durante la época de lluvia, cuando se presentan las temperaturas cálidas en el cual la temperatura muestra los valores más bajos para la región.

Estos resultados llevan a plantear que esta proteína podría estar asociada a los cambios fisiológicos que ocurren durante los procesos de maduración y desove de la especie, o pudiera estar influida directamente por los factores físico-químicos y biológicos que predominen en determinada zona. Es de hacer resaltar que los mayores valores de esta proteína coinciden con el período de alta productividad primaria para la zona costera del oriente venezolano y las más bajas al período de recesión. Esto, extrínsecamente está enmarcado entre temporadas de baja temperatura y elevada producción primaria para la zona, respectivamente.

De acuerdo a lo señalado anteriormente se derivan tres aspectos importantes, los valores de Mts para ambas localidades, aún cuando están separadas espacialmente y existen algunas diferencias de las poblaciones de $P$. viridis en las determinaciones de los índices biométricos y de condición, éstas presentan un patrón similar, lo que permite asegurar que de alguna forma los parámetros físico-químicos que ocurren en la zona, promueven un período bien marcado de alta biomasa fitoplanctónica, que a su vez determinan elevados niveles de la proteína. En segundo lugar, fisiológicamente se determinó que durante los estadios de maduración gonadal la síntesis y movilización de esta proteína es diferente, caracterizada por una mayor concentración en organismos inmaduros, mientras que en los desovados los niveles son menores, lo que sugiere una regulación de la síntesis de Mts asociada a la demanda fisiológica durante el ciclo reproductivo de la especie. En tercer lugar, los aportes antrópicos derivados de las descargas del Delta del Orinoco pudieran estar determinando una mayor concentración de esta proteína hacia la localidad de Río Caribe

Lo anterior sugiere que existe una gran variación en las concentraciones de Mts asociadas a procesos fisiológicos, y que aun no han sido suficientemente estudiadas en bivalvos marinos, pero en este trabajo se hace evidente que el estado de madurez e índice de condición de la especie $P$. viridis modulan su concentración. Aún faltan muchos estudios que permitan dilucidar el papel fisiológico de las Mts en bivalvos.

\section{AGRADECIMIENTO}

Los autores agradecen al Consejo de Investigación de la Universidad de Oriente por el financiamiento de esta investigación.

\section{RESUMEN}

Las metalotioninas (Mts) son proteínas de baja masa molecular que juegan un rol importante en la detoxificación de metales, en vista de su papel ecotoxicológico se evaluaron las metalotioneínas (MTs) en 350 ejemplares del bivalvo Perna viridis en dos localidades de la costa norte del estado Sucre, desde febrero hasta diciembre 2003. Se determinaron los índices biométricos: índice de condición (IC), rendimiento de carne (RC) y relación peso seco-talla (PSL). Las Mts fueron separadas por cromatografía de exclusión molecular, Sephadex G-50 y se cuantificaron por saturación con cadmio. Los índices biométricos (RC y PSL) mostraron variaciones estacionales, entre localidades y estados de madurez, con la excepción del CI. No se encontraron diferencias significativas entre sexos. Las Mts mostraron variaciones estacionales, con concentraciones más elevadas entre febrero y marzo y mínimos entre septiembre y diciembre, que coincidieron con los períodos de alta y baja productividad en el área, respectivamente. Los mejillones de Río Caribe presentaron una mayor concentración de Mts que los de Chacopata. Los mejillones inmaduros mostraron la mayor concentración de Mts y la más baja en los desovados. Se encontró una relación negativa y significativa entre Mts y CI. Los resultados demuestran que las Mts de Perna viridis están influidas por el índice de condición y la condición reproductiva, asi como también pot los factores físico-químicos del ambiente marino.

Palabras clave: metalotioninas, índices biométricos, ciclo gametogénico, Perna viridis. 


\section{REFERENCIAS}

Acosta, V., Y. Natera, C. Lodeiros, L. Freites \& A. Vásqez. 2010. Componentes bioquímicos de los tejidos Perna perna y Perna viridis (Bivalvia: Mytilidae), en relación al crecimiento en condiciones de cultivo suspendido. Lat. Am. J. Aquat. Res. 38: 37-46.

Amiard, J.C., C. Amiard-Triquet, S. Barka, J. Pellerin \& P.S. Rainbow. 2006. Metallothioneins in aquatic invertebrates: their role in metal detoxification and their use as biomarkers. Aquat. Toxicol. 76: 160-202.

Arrieche, D., B. Licet, N. García, C. Lodeiros \& A. Prieto. 2002. Índice de condición gonádico y de densidad del mejillón Marrón Perna perna (Bivalvia: Mytilidae) del Morro de Guarapo Venezuela. Interciencia 27: 613-619.

Baraj, B., F. Niencheski, G. Fillmann \& C.G.M. De Martinez. 2011. Assessing the effects of $\mathrm{Cu}, \mathrm{Cd}$, and exposure period on metallothionein production in gills of the Brazilian brown mussel Perna perna by using factorial design. Environ. Monit. Assess. 179: 155-62.

Bordin, G., J. McCourt, F. Cordeiro-Raposo \& A.R. Rodriguez. 1997. Metallothionein-like metalloproteins in the Baltic clam Macoma baltica: seasonal variations and induction upon metal exposure. Mar. Biol. 129: 453-463.

Bradford, M. 1976. A rapid and sensitive method for the quantitation of microgram quantities of proteins utilizing the principle of protein-dye binding. Anal. Biochem. 72: 248-254.

Cajaraville, M.P., M.J. Bebianno, J. Blasco, C. Porte, C. Sarasquete \& A. Viarengo. 2000. The use of biomarkers to assess the impact of pollution in coastal environments of the Iberian Peninsula: a practical approach. Sci. Total Environ. 247: 295-311.

Coleman, J.E. 1992. Zinc protein: enzymes, storage protein, transcription factor, and replication protein. Ann. Rev. Biochem. 61: 897-946.

Ellman, G. 1959. Tissue sulfhydril groups. Arch. Biochem. Biophys. 82: 70-77.

Eriksen, K., H. Daae \& R. Andersen. 1988. Evidence of presence of heavy metal-binding proteins in polychaete species. Comp. Biochem. Physiol. 91: 377-384.

Farcy, E., C. Voiseux, J.M. Lebel \& B. Fiévet. 2009. Transcriptional expression levels of cell stress marker genes in the Pacific oyster Crassostrea gigas exposed to acute thermal stress. Cell. Stress Chap. 14: 371-80.

García, Y., A. Prieto, J. Marcano, C. Lodeiros \& D. Arrieche. 2005. Producción secundaria del mejillón verde (Perna viridis) (L, 1758), en la península de Araya, Venezuela. Rev. Cient. FCV-LUZ 15: 252-262.
García-Sánchez, A., F. Contreras, M. Adams \& F. Santos. 2006. Atmospheric mercury emissions from polluted gold mining areas (Venezuela). Environ. Geochem. Health. 28: 529-540.

Hemachandra, S T. 2008 Allometry and condition index in green mussel Perna viridis (L.) from St Mary's Island off Malpe, near Udupi, India. Aqua. Res. 39: 1747-1758.

Hickman, R.W. \& J. Illingworth. 1980. Condition cycle of the green lipped mussel Perna canaliculus in New Zealand. Mar. Biol. 60: 27-38.

Khan, M.A.A., Z.B. Assim \& N. Ismail. 2010. Population Dynamics of the Green-Lipped Mussel, Perna viridis from the Offshore Waters of Naf River Coast, Bangladesh. Chiang Mai. J. Sci. 37: 344-354.

Kojima, Y. 1991. Definitions and nomenclature of meta1lothioneins. Methods Enzymol. 205: 8-10.

Lacorn, M., A. Lahrssen, N. Rotzoll, T. Simat \& H. Steinhart. 2001. Quantification of metallothionein isoforms in fish liver and its implications for biomonitoring. Environ. Toxicol. Chem. 20: 140-145.

Legras, S., C. Mouneyrac, J. Amiard \& T. Amiard. 2000. Change in metallothionein concentrations in response to variation in natural factors (salinity, sex, weight) and metal contamination in crabs from a metal-rich estuary. J. Exp. Mar. Biol. Ecol. 246: 259-279.

Leung, K.M.Y., J. Svavarsson, M. Crane \& D. Morritt. 2002. Influence of static and fluctuating salinity on cadmium uptake and metallothionein expression by the dogwelk Nucella lapillus (L.). J. Exp. Mar. Biol. Ecol. 274: 175-189.

Li-Juan, J., M. Wolfgang \& B.L. Vallee. 1998. The ATPmetallothionein complex. Proc. Natl. Acad. Sci. 95: 9146-9149.

Long, A., C. Li, S. Chen, W. Yan, A. Dang, Y. Cheng \& D.J. Lu. 2010. Short-term metal accumulation and MTLP induction in the digestive glands of Perna virdis exposed to Zn and Cd. J. Environ. Sci. 22: 975-981.

Müller-Karger, F., C. McClain, T. Fisher, W. Esaias \& R. Varela. 1989. Pigment distribution in the Caribbean Sea: Observations from space. Prog. Oceanogr. 23: 23-64.

Narasimhan, K. 1980. Fishery and biology of the green mussel Perna viridis (Linnaeus). In: Mussel FarmingProgress and Prospects. Bull. Cent. Mar. Fish. Res. Inst. 29: 10-17.

Ng, T.Y., P.S. Rainbow, C. Amiard-Triquet, J.C. Amiard \& W.X. Wang. 2007. Metallothionein turnover, cytosolic distribution and the uptake of $\mathrm{Cd}$ by the green mussel Perna viridis. Aquat. Toxicol. 84: 153-161.

Prasad, A. 1995. Zinc: Anoverview. Nutrition 11: 93-99.

Rajagopal, S., V. Venugopalan, K. Nair, G. Van der Velde \& H.A. Jenner. 1998. Settlement and growth of the 
green mussel Perna viridis (L) in coastal waters: influence of water velocity. Aquat. Ecol. 32: 313-322.

Rajagopal, S., V.P. Venugopalan, K. Nair, G. Van der Velde \& H.A. Jenner. 2006. Greening of the coast: a review of the Perna viridis success story. Aquat. Ecol. 40: 273-297.

Rojas, N., M. Lemus, L. Rojas, G. Martínez, Y. Ramos \& K. Chung. 2009. Mercury levels in Perna viridis from the north coast of Sucre State, Venezuela. Cienc. Mar. 35: 91-99.

Rylander, J., J. Pérez \& J. Gómez. 1996. Status of the green mussel Perna viridis (Linnaeus, 1758) (Mollusca: Mytilidae) in north easthern Venezuela. Carib. Mar. Stud. 5: 86-87.

Sokal, R. \& F. Rohlf. 1995. Biometry. W.H. Freeman and Company, Nueva York, EE.UU.

Soo-Kyung, R., P. Jin-Sung \& L. In-Sook. 2003. Purification and characterization of a copper-binding protein from Asian periwinkle Littorina brevicula. Comp. Biochem. Physiol. 134: 101-107.
Sureda, A., A. Box, S. Tejada, A. Blanco, J. Caixach \& S. Deudero. 2011. Biochemical responses of Mytilus galloprovincialis as biomarkers of acute environmental pollution caused by the Don Pedro oil spill (Eivissa Island, Spain). Aquat. Toxicol. 101: 540-560.

Uauy, R., M. Olivares \& M. Gonzales. 1998. Essentiality of copper in humans. Am. J. Clin. Nutr. 67: 952-959.

Varela, R., F. Carvajal \& F. Muller-Carger. 2003. El fitoplancton en la plataforma nororiental de Venezuela, p 263-294. In P. Fréon \& J. Mendoza. La sardina, su medio ambiente y explotación en el Oriente de Venezuela. IRD, Venezuela.

Villalejo-Fuerte, M. \& R. Ochoa-Báez. 1993. El ciclo reproductivo de la almeja Catarina Argopecten circularis (Sowerby, 1835), en relación con la temperatura y el fotoperiodo en Bahía Concepción B.C.S., México. Cienc. Mar. 19: 181-202.

Wilbur, K.M. \& G. Owen. 1964. Growth, p. 211-241. In K.M. Wilbur \& C.M. Yonge. Physiology of Mollusca. Academic, Nueva York, EE.UU. 
